\title{
Pharmacological Activation of mGlu4 Metabotropic Glutamate Receptors Reduces Nigrostriatal Degeneration in Mice Treated with 1-Methyl-4-Phenyl-1,2,3,6- Tetrahydropyridine
}

\author{
Giuseppe Battaglia, ${ }^{1}$ Carla L. Busceti, ${ }^{1}$ Gemma Molinaro, ${ }^{1}$ Francesca Biagioni, ${ }^{1}$ Anna Traficante, ${ }^{1}$ \\ Ferdinando Nicoletti, ${ }^{1,2}$ and Valeria Bruno ${ }^{1,2}$ \\ ${ }^{1}$ Istituto Neurologico Mediterraneo Neuromed, 86077 Pozzilli, Italy, and ${ }^{2}$ Department of Human Physiology and Pharmacology, University of Rome "La \\ Sapienza," 00185 Rome, Italy
}

We examined whether selective activation of mGlu4 metabotropic glutamate receptors attenuates 1-methyl-4-phenyl-1,2,3,6tetrahydropyridine (MPTP)-induced nigrostriatal damage in mice. C57BL mice were treated with a single dose of MPTP (30 mg/kg, i.p.) preceded, 30 min earlier, by a systemic injection of the mGlu4 receptor enhancer $\mathrm{N}$-phenyl-7-(hydroxyimino)cyclopropa[b]chromen-1acarboxamide (PHCCC). PHCCC was injected either subcutaneously in cremophor EL or intraperitoneally in saline containing $50 \%$ DMSO. PHCCC treatment ( 3 or $10 \mathrm{mg} / \mathrm{kg}$ ) significantly reduced MPTP toxicity, as assessed by measurements of the striatal levels of dopamine and its metabolites and by tyrosine hydroxylase, dopamine transporter, and glial fibrillary acidic protein immunostaining in the corpus striatum and substantia nigra. In another set of experiments, a higher cumulative dose of MPTP ( $80 \mathrm{mg} / \mathrm{kg}$ divided into four injections with $2 \mathrm{~h}$ of interval) was injected to $m \mathrm{Glu}^{-/-}$mice and their Sv129/CD1 wild-type controls. A higher dose was used in these experiments because Sv129/CD1 mice are less sensitive to MPTP toxicity. Systemic administration of PHCCC was protective in wild-type mice but failed to affect nigrostriatal damage in $m \mathrm{Glu}^{-/-}$mice. Finally, unilateral infusion of PHCCC in the external globus pallidus protected the ipsilateral nigrostriatal pathway against MPTP toxicity. These data support the view that mGlu4 receptors are potential targets for the experimental treatment of parkinsonism.

Key words: basal ganglia; dopamine; MPTP toxicity; mGlu4 receptors; neuroprotection; experimental parkinsonism

\section{Introduction}

Despite extensive research, L-3,5-dihydroxyphenylalanine (LDOPA) is still the gold standard in the treatment of Parkinson's disease. However, long-term administration of L-DOPA is complicated by fluctuations of its therapeutic efficacy ("wearing-off," "drug-resistant off," and "on-off" phenomena) and by the occurrence of dyskinesias (Bedard et al., 1999). These limitations are partially overcome by the use of dopamine receptor agonists and anticholinergic drugs, which, however, show relatively low efficacy and induce several adverse effects (for review, see Rascol, 2000). More important, none of these drugs arrest or retard the progression of the disorder, and, under some circumstances, L-DOPA may even promote oxidative damage of nigral neurons (Graham, 1978). This strongly encourages the search for novel drugs that relieve motor symptoms of parkinsonism and attenuate the ongoing degeneration of nigrostriatal neurons at the same

Received Sept. 29, 2005; revised May 19, 2006; accepted May 20, 2006.

This work was supported by Ministero dell'Istruzione, dell'Università, e della Ricerca COFIN 2004 Protocol number 2004052809 (F.N.).

Correspondence should be addressed to Dr. Valeria Bruno, Department of Human Physiology and Pharmacology, University of Rome “La Sapienza," Piazzale Aldo Moro 5, 00185 Rome, Italy. E-mail: nicoletti@neuromed.it.

D0I:10.1523/JNEUROSCI.1595-06.2006

Copyright $\odot 2006$ Society for Neuroscience $\quad 0270-6474 / 06 / 267222-08 \$ 15.00 / 0$ time. Recently, attention has been focused on metabotropic glutamate (mGlu) receptors, which are widely distributed in the basal ganglia motor circuit (for review, see Conn et al., 2005) and have an established role in mechanisms of neurodegeneration/ neuroprotection (Bruno et al., 2001). mGlu receptors form a family of eight subtypes (mGlu1 to mGlu8), which are subdivided into three groups on the basis of their sequence homology, pharmacological profile, and transduction pathways. Group I includes mGlu1 and mGlu5 receptors, which are coupled to $\mathrm{G}_{\mathrm{q}}$ proteins. Their activation stimulates polyphosphoinositide hydrolysis generating inositol-1,4,5-trisphosphate and diacylglycerol. Group II includes mGlu2 and mGlu3 receptors, which are coupled to $\mathrm{G}_{\mathrm{i}}$-proteins. Group III includes mGlu4, mGlu6, mGlu7, and mGlu8 receptors, which are also coupled to $\mathrm{G}_{\mathrm{i}^{-}}$ proteins in heterologous expression systems (for review, see Pin and Duvoisin, 1995; De Blasi et al., 2001). The study of mGlu receptors is now facilitated by the availability of potent and subtype-selective ligands, including negative or positive allosteric modulators. Allosteric modulators are particularly helpful because they inhibit or amplify receptor function independently of the concentrations of ambient glutamate and are effective at synapses that are tonically activated by endogenous glutamate. Recent evidence indicates that intracerebroventricular injection of 

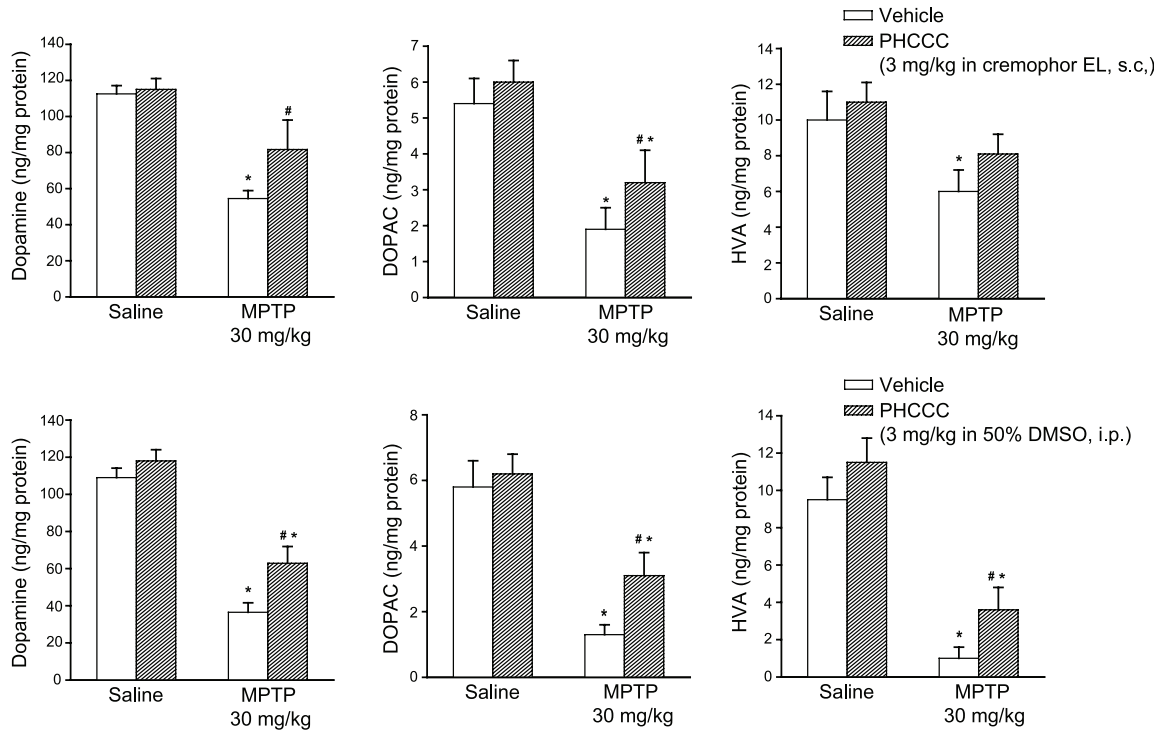

Figure 1. Striatal dopamine, DOPAC, and HVA levels in C57BL mice injected with MPTP ( $30 \mathrm{mg} / \mathrm{kg}$, i.p., single injection) alone or in combination with PHCCC ( $3 \mathrm{mg} / \mathrm{kg}$ ) either dissolved in cremophor EL and injected subcutaneously 30 min before MPTP or dissolved in DMSO 50\% and injected intraperitoneally 30 min before MPTP. Values are mean \pm SEM of $8-10$ determinations; $p<$ 0.05 (one-way ANOVA and Fisher's PLSD test) versus saline-treated mice $\left(^{*}\right)$ or versus mice treated with MPTP alone (\#).

Cookson (Bristol, UK). All other chemicals were purchased from Sigma (Milan, Italy).

Animals. C57BL mice (22-24 g, body weight) were purchased from Charles River (Calco, Italy) and used for experiments with low doses of MPTP. Hybrid homozygous knock-out $\left(m \mathrm{Glu}^{-/-}\right)$mice (strain name, STOCK Gprc1d ${ }^{\text {tm1Hpn }}$; stock number 003576) (22-24 g, body weight) were obtained from The Jackson Laboratory (Bar Harbor, ME). 129Sv and CD1 mice (22-24 g, body weight; Charles River) were backcrossed to obtain controls for $m \mathrm{Glu}^{-1-}$ mice and used in experiments with high doses of MPTP. Mice were kept under environmentally controlled conditions (ambient temperature, $22^{\circ} \mathrm{C}$; humidity, $40 \%$ ) on a $12 \mathrm{~h}$ light/dark cycle with food and water ad libitum. Experiments were performed following the Guidelines for Animal Care and Use of the National Institutes of Health.

Treatments. C57BL mice were treated with a single intraperitoneal injection of $36 \mathrm{mg} / \mathrm{kg}$ MPTP (corresponding to $30 \mathrm{mg} / \mathrm{kg}$ free MPTP) and killed $7 \mathrm{~d}$ later for the biochemical or immunohistochemical assessment of nigrostriatal damage. An independent group of C57BL mice was used for measurements of 1-methyl-4phenyl-pyridinium ion $\left(\mathrm{MPP}^{+}\right)$or MPTP in the striatum. When needed, PHCCC was in-

the group III mGlu receptor agonist L-2-amino-4phosphonobutanoate (L-AP-4) relieves motor symptoms in multiple animal models of parkinsonism and is as efficacious as L-DOPA in decreasing forelimb asymmetry in rats unilaterally lesioned with 6-hydroxydopamine (Valenti et al., 2003; Mac Innes et al., 2004). The action of L-AP-4 is mimicked by $N$-phenyl-7-(hydroxyimino)cyclopropa[b] chromen 1a-carboxamide (PHCCC), which behaves as a selective allosteric potentiator of mGlu4 receptors with no direct agonist activity and no potentiator activity on any other mGlu receptor subtype (Maj et al., 2003; Marino et al., 2003). The symptomatic activity of L-AP-4 and PHCCC is mediated by presynaptic mGlu4 receptors localized on GABAergic fibers projecting from the neostriatum (caudate nucleus/putamen) to the external globus pallidus, which are part of the "indirect pathway" of motor control in the basal ganglia motor circuit. Activation of mGlu4 receptors mimics the action of dopamine in reducing GABA release in the external globus pallidus. This leads to a disinhibition of GABAergic neurons projecting from the external globus pallidus to the subthalamic nucleus, with an ensuing inhibition of glutamatergic neurons of the subthalamic nucleus, which project to the internal globus pallidus and the pars reticulata of the substantia nigra. The following disinhibition of thalamocortical neurons results into an improvement of parkinsonian symptoms (Marino et al., 2003; Valenti et al., 2003). Because neurons of the subthalamic nucleus also project to the pars compacta of the substantia nigra, one can predict that activation of mGlu4 receptors reduces the excitotoxic component of nigrostriatal degeneration in experimental models of parkinsonism. Accordingly, we now show that systemic injection of PHCCC attenuates nigrostriatal degeneration in mice challenged with the parkinsonian toxin 1-methyl-4-phenyl-1,2,3,6tetrahydropyridine (MPTP) and that the action of PHCCC requires the presence of $\mathrm{mGlu} 4$ receptors.

\section{Materials and Methods}

Materials. PHCCC and 7-hydroxyiminocyclopropan[b]chromen-1acarboxylic acid ethyl ester (CPCCOEt) were purchased from Tocris jected 30 min before MPTP injection. PHCCC was either dissolved in saline containing 50\% DMSO and injected intraperitoneally or dissolved in the lipid solvent cremophor EL and injected subcutaneously. Control mice were injected with the vehicle alone. Wild-type Sv129/CD1 mice or $m \mathrm{Glu}^{-/-}$mice were instead challenged with four doses of $24 \mathrm{mg} / \mathrm{kg}$ MPTP hydrochloride (corresponding to $20 \mathrm{mg} / \mathrm{kg}$ free MPTP), injected intraperitoneally with $2 \mathrm{~h}$ of interval (cumulative dose, $80 \mathrm{mg} / \mathrm{kg}$ free MPTP). PHCCC was only administered subcutaneously to these mice. In another set of experiments, male C57BL mice were used to measure the effect of PHCCC unilaterally infused in the external globus pallidus. Mice were implanted with intracerebral guide cannulas (Bilaney, Düsseldorf, Germany), under ketamine (100 mg/kg) plus xylazine (10 mg/kg) intraperitoneal anesthesia, in a David Kopf Instruments (Tujunga, CA) stereotaxic frame. The site of implantation was the left external globus pallidus (coordinates, $0.5 \mathrm{~mm}$ posterior to the bregma, $1.9 \mathrm{~mm}$ lateral to the midline, $2.8 \mathrm{~mm}$ ventral from the surface of skull according to the atlas of Franklin and Paxinos, 1997). After surgery, mice were housed in separate cages and allowed to recover for $3 \mathrm{~d}$ before the experiment. On the day of the experiment, an internal cannula extending $1 \mathrm{~mm}$ out of the intracerebral guide was inserted, after removing a dummy, and PHCCC ( $20 \mathrm{nmol} / 0.5 \mu \mathrm{l}$, dissolved in saline containing 50\% DMSO) was injected at a flow rate of $0.25 \mu \mathrm{l} / \mathrm{min}$ using a microinjection pump (Bioanalytical System, West Lafayette, IN). Additional mice were injected unilaterally with the vehicle alone and used as controls. Thirty minutes later, animals were treated with a single intraperitoneal injection of $36 \mathrm{mg} / \mathrm{kg}$ MPTP (corresponding to $30 \mathrm{mg} / \mathrm{kg}$ free MPTP) and killed $7 \mathrm{~d}$ later for the biochemical or immunohistochemical assessment of nigrostriatal damage and for Nissl staining in the substantia nigra.

Assessment of reserpine-induced akinesia. Mice were injected with reserpine $(2.5 \mathrm{mg} / \mathrm{kg}$ s.c., dissolved in $1 \%$ acetic acid) and kept in their home cages for the following $20 \mathrm{~h}$. PHCCC ( 3 or $10 \mathrm{mg} / \mathrm{kg}$, dissolved in cremophor EL) was injected subcutaneously $18 \mathrm{~h}$ after reserpine injection. Akinesia was assessed 30 or $120 \mathrm{~min}$ after PHCCC or vehicle injection by measuring the immobility time after placing the forepaws of the animals on a horizontal bar or by measuring the time spent in an abnormal posture ("Buddha-like position") at the corner of their own cage.

Tyrosine hydroxylase, dopamine transporter, and glial fibrillary acidic protein immunostaining. Brains were dissected out and immediately placed in a solution composed of ethyl alcohol (60\%), acetic acid (10\%), and chloroform (30\%). Twenty hours later, brains were placed in $70 \%$ 
ethanol until they were included in paraffin. Ten $\mu \mathrm{m}$ serial sections were cut and used for histological analysis. Tissue sections were incubated overnight with monoclonal mouse antibody (1:200; Sigma, St. Louis, MO), with monoclonal rat antibody (1:200; Chemicon, Temecula, CA), or with monoclonal mouse antibody (1:400; Sigma, St. Louis, MO) for the detection of tyrosine hydroxylase (TH), dopamine transporter (DAT), and glial fibrillary acidic protein (GFAP), respectively, and then for $1 \mathrm{~h}$ with secondary biotin-coupled antimouse and anti-rat (1:200; Vector Laboratories, Burlingame, CA) antibodies for the detection of $\mathrm{TH}$ and DAT, respectively, and fluorescein isothiocyanate-conjugated horse anti-mouse $\operatorname{IgG}(1: 100$; Vector Laboratories) for the detection of GFAP. Control staining was performed without the primary antibodies. TH and DAT immunoreactivity was quantified by measuring the relative optical densities of the dorsal striatum in the stained sections using a computerbased microdensitometer (NIH Image). Adjacent tissue sections were stained with cresyl violet. The number of Nissl-stained cells in the par compacta of the substantia nigra was counted in 10 sections, $10 \mu \mathrm{m}$ thick, cut every $100 \mu \mathrm{m}$. The number of TH-positive cells was counted in adjacent sections. Cell counts were determined as follows: (1) the area of the pars compacta of substantia nigra was determined at low magnification $(5 \times$ objective $)$ in each section; (2) neurons were counted at higher magnification ( $100 \times$ objective) (Thiruchelvam et al., 2004) in three microscopic fields (corresponding to an area of $14,462 \mu \mathrm{m}^{2}$ each) selected along the mediolateral axis of the substantia nigra in each section; (3) the total number of neurons in each section was calculated using the following formula: (average number of the 3 microscopic sections/14,462 $\mu \mathrm{m}^{2}$ ) $\times$ area of the section (in square micrometers); and (4) neuronal density was calculated as the ratio between the sum of neuronal counts and the sum of the areas of all 10 sections and were expressed as number per square micrometer. Although this semiquantitative analysis is not an unbiased stereologic method, the counting was considered reliable because the number of neurons calculated from the average of three microscopic fields at high magnification (100× objective) approximately corresponded to the number of neurons directly assessed at low magnification ( $5 \times$ objective) in representative $10 \mu \mathrm{m}$ sections.

Monoamine assay. The corpus striatum was homogenized by sonication in $0.6 \mathrm{ml}$ of ice-cold $0.1 \mathrm{~m}$ perchloric acid (PCA). Fifty microliters of the homogenate were used for protein determination (Lowry et al., 1951). The remaining aliquot was centrifuged at $8000 \times g$ for $10 \mathrm{~min}$, and $20 \mu \mathrm{l}$ of the supernatant was injected into an HPLC equipped with an autosampler 507 (Beckman Instruments, Fullerton, CA), a programmable solvent module 126 (Beckman Instruments), an analytical C-18 reverse-phase column kept at $30^{\circ} \mathrm{C}$ (Ultrasphere ODS $5 \mathrm{~mm}, 80 \AA$ pore, $250 \times 4.6 \mathrm{~mm}$; Beckman Instruments), and a Coulochem II electrochemical detector (ESA, Chelmsford, MA). The holding potentials were set at +350 and $-350 \mathrm{mV}$ for the detection of dopamine, 3,5dihydroxyphenylactic acid (DOPAC), and homovanillic acid (HVA). The mobile phase consisted of $80 \mathrm{~mm}$ sodium phosphate, $40 \mathrm{~mm}$ citric acid, 0.4 mm EDTA, 3 mm 1-heptansulphonic acid, and 8.5\% methanol, brought to $\mathrm{pH} 2.75$ with phosphoric acid (run under isocratic conditions at $1 \mathrm{ml} / \mathrm{min}$ ).
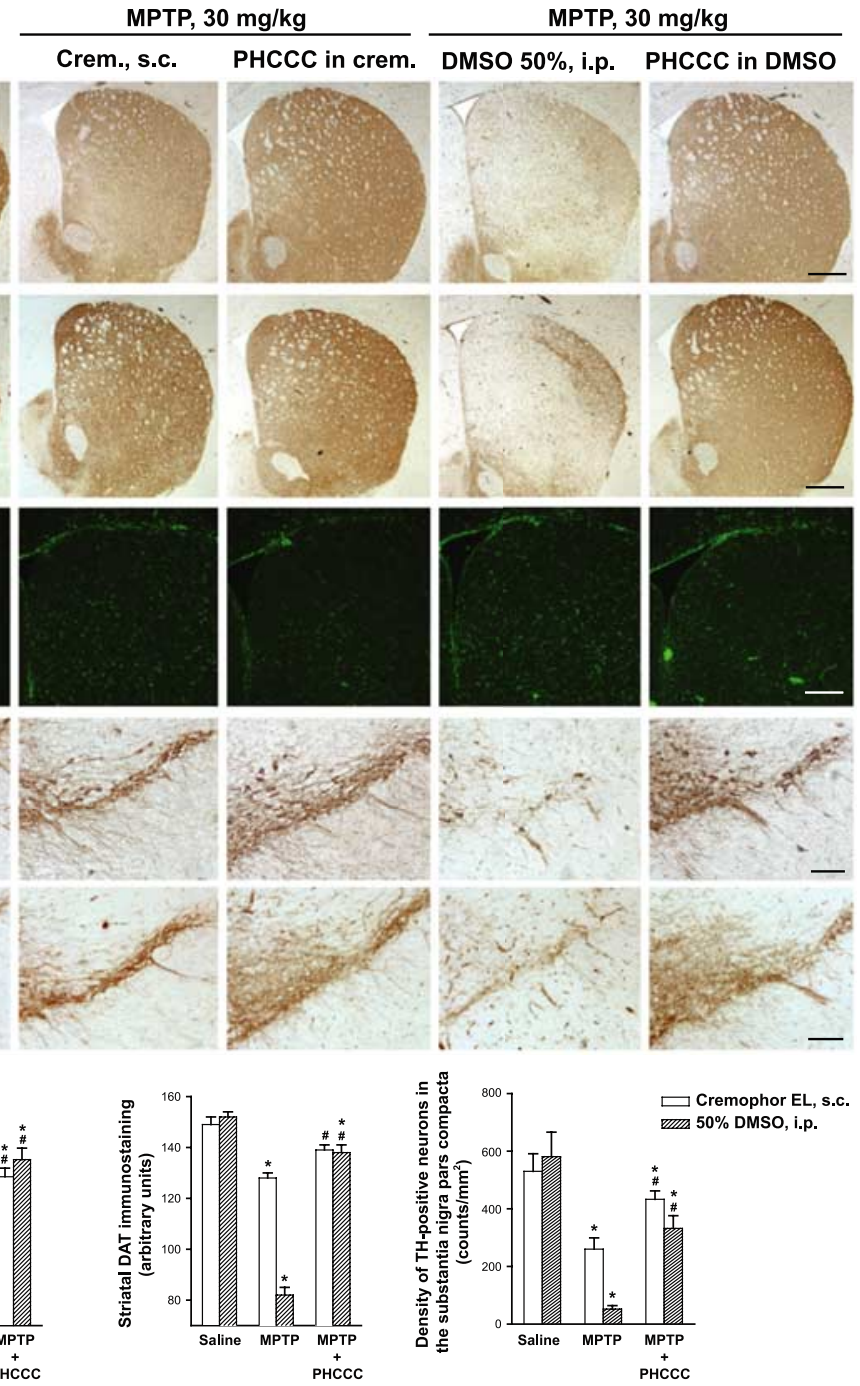
$50 \%$ DMSO, i.p.

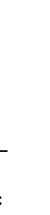

Figure 2. Immunohistochemical analysis of TH, DAT, and GFAP in the corpus striatum and pars compacta of substantia nigra of , $200 \mu \mathrm{m}$; TH and DAT in the substantia nigra, $100 \mu \mathrm{m}$. Densitometric data are shown below. Values (means \pm SEM) were the density of TH-positive neurons in the pars compacta of the substantia nigra). $p<0.05$ (one-way ANOVA and Fisher's PLSD test) versus saline-treated mice $\left({ }^{*}\right)$ or mice treated with MPTP alone (\#).

Measurement of body temperature. To test whether PHCCC produced hypothermia, we measured body temperature in control mice and in mice injected with MPTP. Mice were treated with vehicle (50\% DMSO in saline) or PHCCC (3 mg/kg, dissolved in 50\% DMSO) $30 \mathrm{~min}$ before MPTP (30 mg/kg, i.p.) or saline injection. Body temperature was measured $60 \mathrm{~min}$ after saline or MPTP injection. Core temperature was measured by inserting a thermometer probe lubricated with oil at least $3 \mathrm{~cm}$ into the rectum of mice.

Assay of MPTP and MPP ${ }^{+}$levels. Groups of five mice, treated with vehicle or PHCCC (3 mg/kg, i.p.) and injected with MPTP hydrochloride in a single injection $(36 \mathrm{mg} / \mathrm{kg}$, i.p.) were used for measurements of MPTP and $\mathrm{MPP}^{+}$levels in the striatum at different time points after MPTP injection. The corpus striatum was homogenized by sonication in $0.6 \mathrm{ml}$ of ice-cold $0.1 \mathrm{M}$ PCA. Fifty microliters of the homogenate were used for protein determination (Lowry et al., 1951). The remaining aliquot was centrifuged at $8000 \times g$ for $10 \mathrm{~min}$, and $20 \mu \mathrm{l}$ of the supernatant was injected into an HPLC equipped with an autosampler 507 (Beckman Instruments), a programmable solvent module 125 (Beckman Instruments), an analytical C-18 reverse-phase column kept at $30^{\circ} \mathrm{C}$ (Ultrasphere ODS $5 \mu \mathrm{m}, 80 \AA$ pore, $150 \times 2 \mathrm{~mm}$; Beckman Instruments), and 
a 166 UV detector (Beckman Instruments). The mobile phase consisted of $0.1 \mathrm{M}$ sulfuric acid, $10 \%$ acetonitrile, and $75 \mathrm{~mm}$ triethylamine at $\mathrm{pH}$ 2.3 (run under isocratic conditions at $0.3 \mathrm{ml} / \mathrm{min}$ ). The UV detector was set to $295 \mathrm{~nm}$ for $\mathrm{MPP}^{+}$detection and was automatically switched to 245 nm for MPTP, as described previously (Fornai et al., 1997).

Measurement of $\left[{ }^{3} \mathrm{H}\right] \mathrm{MPP}{ }^{+}$uptake in striatal synaptosomes. Synaptosomes were prepared as described previously by Bonnet and Costentin (1989), with minor modifications. Briefly, mouse striata were homogenized in $20 \mathrm{vol}$ of $0.32 \mathrm{~m}$ sucrose using a Teflon-glass homogenizer. The homogenates were then centrifuged at $1000 \times g$ for $10 \mathrm{~min}$ at $4^{\circ} \mathrm{C}$ to give a nuclear pellet. Supernatants were stored at $4^{\circ} \mathrm{C}$, and the pellet was resuspended in $20 \mathrm{vol}$ of $0.32 \mathrm{M}$ sucrose and centrifuged for $10 \mathrm{~min}$ at $1000 \times g$. The two supernatants were then pooled and centrifuged at $17,500 \times g$ for $30 \mathrm{~min}$ at $4^{\circ} \mathrm{C}$, after which the supernatant was discarded and the final pellet was resuspended in ice-cold Krebs'-Ringer's buffer (in mM: $120 \mathrm{NaCl}, 4.8 \mathrm{KCl}, 1.3 \mathrm{CaCl}_{2}, 1.2 \mathrm{MgSO}_{4}, 1.2 \mathrm{KH}_{2} \mathrm{PO}_{4}, 25$ $\mathrm{NaHCO}_{3}$, and 6 glucose, $\mathrm{pH}$ 7.6). Synaptosomes ( $25 \mathrm{mg}$ of protein) were incubated in $1 \mathrm{ml}$ of Krebs'-Ringer's buffer with $\left[{ }^{3} \mathrm{H}\right] \mathrm{MPP}^{+}(5 \mathrm{~nm}$; specific activity, $71.4 \mathrm{Ci} / \mathrm{mmol}$; PerkinElmer, Boston, MA) for $2 \mathrm{~min}$ at $37^{\circ} \mathrm{C}$. Nonspecific $\mathrm{MPP}^{+}$uptake was measured in the presence of $500 \mu \mathrm{M}$ $\mathrm{MPP}^{+}$. When present, PHCCC $(0.01-10 \mu \mathrm{M})$ was added. MPP ${ }^{+}$uptake was stopped by addition of $3 \mathrm{ml}$ of ice-cold Krebs'-Ringer's buffer. The suspension was immediately filtered under vacuum through Whatman (Maidstone, UK) GF/C filters. Radioactivity was determined by liquid scintillation spectrometry. Specific $\left[{ }^{3} \mathrm{H}\right] \mathrm{MPP}^{+}$uptake, defined as the difference between $\left[{ }^{3} \mathrm{H}\right] \mathrm{MPP}{ }^{+}$accumulated at $37^{\circ} \mathrm{C}$ in the presence and absence of $\mathrm{MPP}^{+}$, was expressed as femtomoles per milligram of protein. Protein content was measured by the method of Lowry et al. (1951) using bovine serum albumin as standard.

\section{Results}

C57BL mice were challenged with a single dose of MPTP (30 $\mathrm{mg} / \mathrm{kg}$, i.p.), which led, $7 \mathrm{~d}$ later, to a $50-65 \%$ reduction in striatal dopamine levels. Similar reductions were found in the striatal levels of DOPAC and HVA, although changes in HVA levels were variable in different experiments (Fig. 1). Reductions in dopamine and its metabolites were attenuated in mice injected with 3 $\mathrm{mg} / \mathrm{kg}$ PHCCC $30 \mathrm{~min}$ before MPTP. PHCCC was protective when injected subcutaneously in the lipid solvent cremophor EL and when injected intraperitoneally in a saline solution containing 50\% DMSO (Fig. 1). Note that, for unknown reasons, MPTP toxicity was greater in control animals injected with 50\% DMSO alone. A higher dose of PHCCC (10 mg/kg, s.c.) did not further reduce striatal dopamine, DOPAC, and HVA levels (data not shown), suggesting that the dose of $3 \mathrm{mg} / \mathrm{kg}$ PHCCC was saturating. Treatment with CPCCOEt $(10 \mathrm{mg} / \mathrm{kg}$, i.p. $)$, a restricted structural analog of PHCCC (Annoura et al., 1996), had no effect on MPTP neurotoxicity (data not shown) (Battaglia et al., 2003). Neuroprotection by PHCCC was confirmed by a higher TH and DAT immunostaining in the corpus striatum and substantia nigra, a lower GFAP immunostaining in the corpus striatum (reflecting a lower extent of reactive gliosis), and by a greater number of $\mathrm{TH}$-positive neurons in the pars compacta of substantia nigra (Fig. 2). In an additional experiment, mice were treated with $30 \mathrm{mg} / \mathrm{kg}$ MPTP alone or with MPTP plus $3 \mathrm{mg} / \mathrm{kg}$ PHCCC (injected either intraperitoneally or subcutaneously), and Nisslstained neurons in the pars compacta of the substantia nigra were counted. The reduction of nigral neurons was less substantial in mice pretreated with PHCCC (Fig. 3), indicating that data obtained with $\mathrm{TH}$ immunostaining do not reflect changes in the expression of the enzyme. Under our conditions (single injection of MPTP at the dose of $30 \mathrm{mg} / \mathrm{kg}$ ), we did not find any change in the core body temperature among mice treated with saline, MPTP alone, PHCCC (3 mg/kg, i.p.), or MPTP combined with PHCCC (Table 1). To exclude any possible interference of $\mathrm{PH}$ -
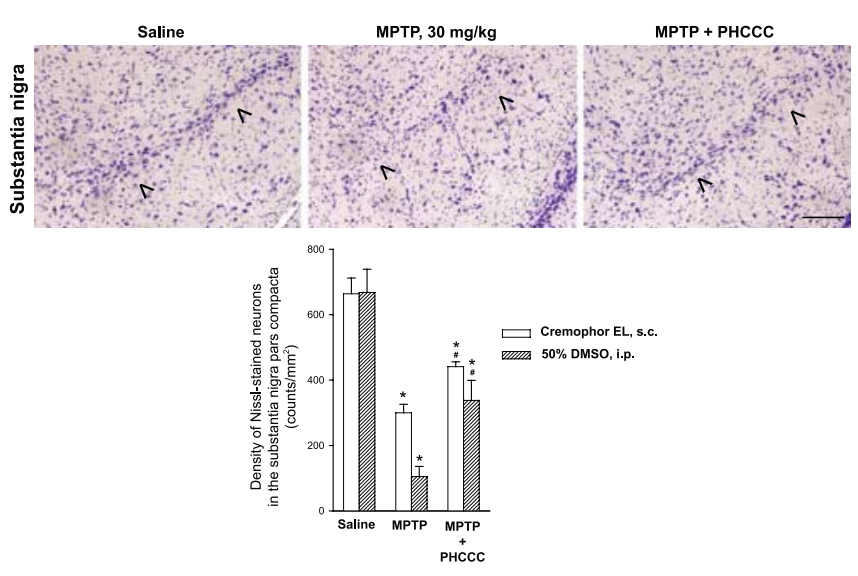

Figure 3. $\boldsymbol{A}$, Representative Nissl staining of neurons in the pars compacta of the substantia nigra of mice treated with $30 \mathrm{mg} / \mathrm{kg}$ MPTP alone or combined with $3 \mathrm{mg} / \mathrm{kg}$ PHCCC (dissolved in saline containing 50\% DMSO). Scale bar, $200 \mu \mathrm{m}$. B, Quantification of Nissl-stained cells in the pars compacta of the substantia nigra of mice treated with $30 \mathrm{mg} / \mathrm{kg}$ MPTP alone or combined with $3 \mathrm{mg} / \mathrm{kg}$ PHCCC (dissolved either in cremophor EL and injected subcutaneously or in saline containing 50\% DMSO and injected intraperitoneally). The density of Nissl-stained neurons was calculated from counts obtained in 10 sections ( $10 \mu \mathrm{m}$ each, cut every $100 \mu \mathrm{m}$ ) as described in Materials and Methods. Values are means \pm SEM of numbers from five to six mice. $p<0.05$ (one-way ANOVA and Fisher's PLSD test) versus saline-treated mice $\left(^{*}\right)$ or mice treated with MPTP alone (\#).

Table 1. Measurements of body temperature in control and MPTP-injected mice treated with PHCCC

\begin{tabular}{ll}
\hline Treatments & $\begin{array}{l}\text { Body temperature } \\
\left({ }^{\circ} \mathrm{C}\right), 60 \mathrm{~min}\end{array}$ \\
\hline Saline & $37.2 \pm 0.2$ \\
MPTP $(30 \mathrm{mg} / \mathrm{kg}$, i.p. $)$ & $36.7 \pm 0.5$ \\
PHCCC $(3 \mathrm{mg} / \mathrm{kg}$, i.p. $)$ & $36.8 \pm 0.7$ \\
MPTP + PHCCC & $36.6 \pm 0.6$ \\
\hline
\end{tabular}

Body temperature was measured $60 \mathrm{~min}$ after injection of MPTP $(30 \mathrm{mg} / \mathrm{kg}$, i.p.). Effect of PHCCC ( $3 \mathrm{mg} / \mathrm{kg}$, i.p.) on body temperature was measured $1 \mathrm{hr}$ after MPTP injection. Values are mean \pm SEM of four animals for each group.

CCC with the distribution kinetics and bioactivation of MPTP, we measured the striatal levels of $\mathrm{MPP}^{+}$(the toxic metabolite of MPTP) in C57BL mice at different times after injection of 30 $\mathrm{mg} / \mathrm{kg}$ MPTP combined or not with $3 \mathrm{mg} / \mathrm{kg}$ PHCCC (injected subcutaneously in cremophor EL 30 min before MPTP). PHCCC had no discernible effect on the kinetics of $\mathrm{MPP}^{+}$formation in the striatum (Fig. 4A). Striatal MPTP levels were only detected 30 min after MPTP injection and did not differ between control mice and mice treated with PHCCC (data not shown). We also examined the effect of PHCCC on $\left[{ }^{3} \mathrm{H}\right] \mathrm{MPP}^{+}$uptake in striatal synaptosomal preparations. $\mathrm{PHCCC}$ added to synaptosomes had no effect on $\left[{ }^{3} \mathrm{H}\right] \mathrm{MPP}^{+}$uptake at concentrations of $0.01-10 \mu \mathrm{M}$ (Fig. 4B). To confirm that peripherally injected PHCCC at the doses used in our experiments can penetrate the brain, we assessed the ability of the drug to revert reserpine-induced akinesia (Rivas et al., 1999). Mice were treated subcutaneously with 2.5 $\mathrm{mg} / \mathrm{kg}$ reserpine and challenged intraperitoneally with 3 or 10 $\mathrm{mg} / \mathrm{kg}$ PHCCC $18 \mathrm{~h}$ later. Akinesia was assessed by measuring the immobility time of the mice placed with their forepaws on a horizontal bar or the time they spent in an abnormal posture (a Buddha-like position at the corner of their own cage). Mice treated with PHCCC showed a significant reduction in the immobility time in both tests (results of the horizontal bar test are shown in Fig. 5).

In an attempt to circumscribe the anatomical site responsible for the protective activity of PHCCC against MPTP toxicity, we 

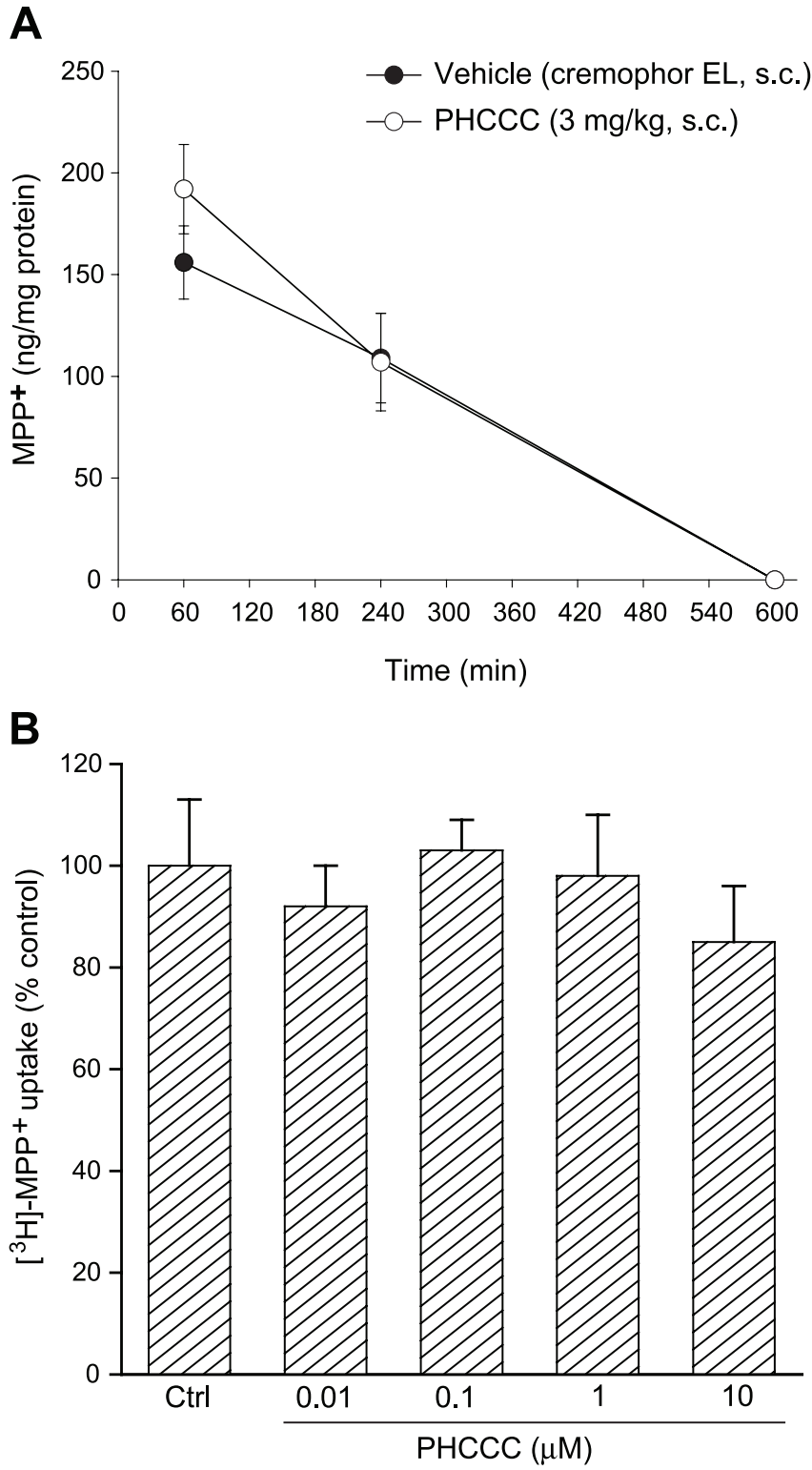

Figure 4. $\quad A$, In vivo measurements of MPP ${ }^{+}$levels in mouse striatal homogenates, prepared from C57BL mice, at different times after injection of $30 \mathrm{mg} / \mathrm{kg} \mathrm{MPTP}$ and $3 \mathrm{mg} / \mathrm{kg}$ PHCCC (dissolved in cremophor EL and injected subcutaneously $30 \mathrm{~min}$ before MPTP). Data are mean \pm SEM of five determinations. $\boldsymbol{B}$, Measurements of $\left[{ }^{3} \mathrm{H}\right] \mathrm{MPP}{ }^{+}$uptake in mouse striatal synaptosomes incubated with $\mathrm{PHCCC}(0.01-10 \mu \mathrm{M})$. Values are expressed as percentage of $\mathrm{MPP}^{+}$uptake in striatal synaptosomes (Ctrl) and are means \pm SEM of four determinations. Control values of $\left[{ }^{3} \mathrm{H}\right] \mathrm{MPP}{ }^{+}$uptake are $250 \pm 11 \mathrm{fmol} / \mathrm{mg}$ protein for $2 \mathrm{~min}$.

unilaterally infused PHCCC in the left external globus pallidus (20 nmol/0.5 $\mu \mathrm{l}$ saline solution containing 50\% DMSO for 2 min) $30 \mathrm{~min}$ before MPTP (30 mg/kg) and assessed the viability of the nigrostriatal pathway by counting neurons in the ipsilateral substantia nigra and by assessing TH immunostaining or measuring dopamine, DOPAC, and HVA levels in the ipsilateral corpus striatum. Unilateral infusion of PHCCC reduced MPTP toxicity in the ipsilateral substantia nigra and corpus striatum to an extent similar to that observed after peripheral injection of the drug, whereas unilateral infusion of the vehicle alone $(50 \%$ DMSO in saline) was not protective (Fig. 6).

Finally, we explored whether the protective effect of PHCCC was mediated by mGlu4 receptors. We addressed this issue by using $m \mathrm{Glu}^{-/-}$mice because of the lack of centrally active selec-

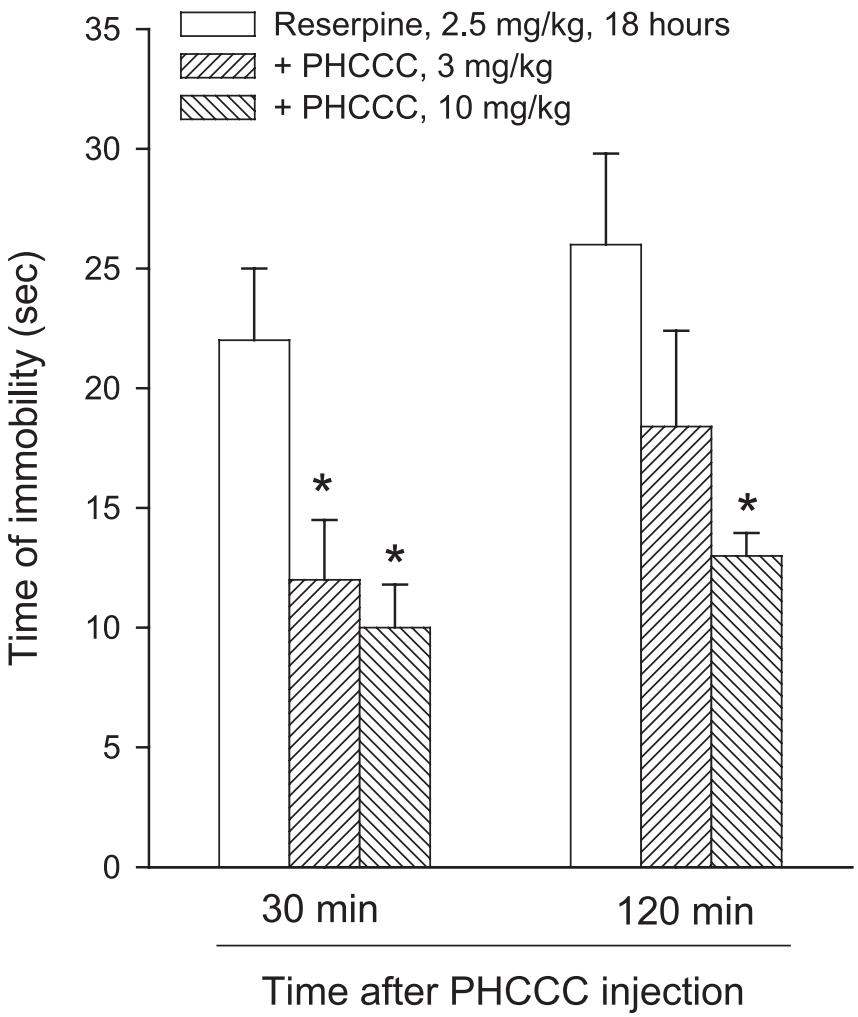

Figure 5. Assessment of reserpine-induced akinesia. Mice were injected with reserpine ( 2.5 $\mathrm{mg} / \mathrm{kg}$ ) and challenged intraperitoneally with 3 or $10 \mathrm{mg} / \mathrm{kg}$ PHCCC (dissolved in saline containing 50\% DMSO) $18 \mathrm{~h}$ later. Akinesia was assessed 30 and 120 min after PHCCC or vehicle injection by measuring the immobility time in a horizontal bar. Values are mean $\pm \mathrm{SEM}$ of five to six mice. $p<0.05$ (one-way ANOVA and Fisher's PLSD test) versus control mice injected with vehicle $\left.{ }^{*}\right)$.

tive mGlu4 receptor antagonists. We compared the effect of PHCCC on MPTP toxicity in $m \mathrm{Glu}^{-/-}$mice and Sv129/CD1 wild-type control mice. This particular strain of mice was more resistant to MPTP toxicity and responded to a single administration of $30 \mathrm{mg} / \mathrm{kg}$ MPTP with $<25 \%$ reduction in striatal DA levels (data not shown). For this reason, we challenged Sv129/ CD1 mice with a higher dose of MPTP $(80 \mathrm{mg} / \mathrm{kg}$, i.p., divided into four injections of $20 \mathrm{mg} / \mathrm{kg}$ with $2 \mathrm{~h}$ of interval), which caused the death of 5 of 12 animals and led to $\sim 80-85 \%$ reduction of striatal dopamine, DOPAC, and HVA levels in surviving mice (Fig. 7). Injection of $80 \mathrm{mg} / \mathrm{kg}$ MPTP in $\mathrm{mGlu}^{-/-}$mice caused the death of 7 of 14 animals and reductions in striatal DA, DOPAC, and HVA levels similar to those seen in wild-type mice (Fig. 8). PHCCC (3 mg/kg, dissolved in cremophor EL and injected subcutaneously $30 \mathrm{~min}$ before each injection of MPTP) protected wild-type Sv129/CD1 mice against MPTP toxicity but was inactive in $\mathrm{mGlu}^{-/-}$mice (Fig. 7). The lack of activity of PHCCC in $m \mathrm{Glu}^{-/-}$mice was confirmed by the assessment of $\mathrm{TH}$ and DAT immunostaining in the corpus striatum and substantia nigra (Fig. 8).

\section{Discussion}

The MPTP mouse model is widely used for the screening of neuroprotective drugs of potential use in the treatment of Parkinson's disease. MPTP is a lipophilic toxin that crosses the bloodbrain barrier and is converted into the active metabolite $\mathrm{MPP}^{+}$. $\mathrm{MPP}^{+}$is transported by the DAT into striatal dopaminergic terminals, in which it behaves as a mitochondrial toxin killing nigrostriatal neurons (for review, see Przedporski and Jackson- 
A
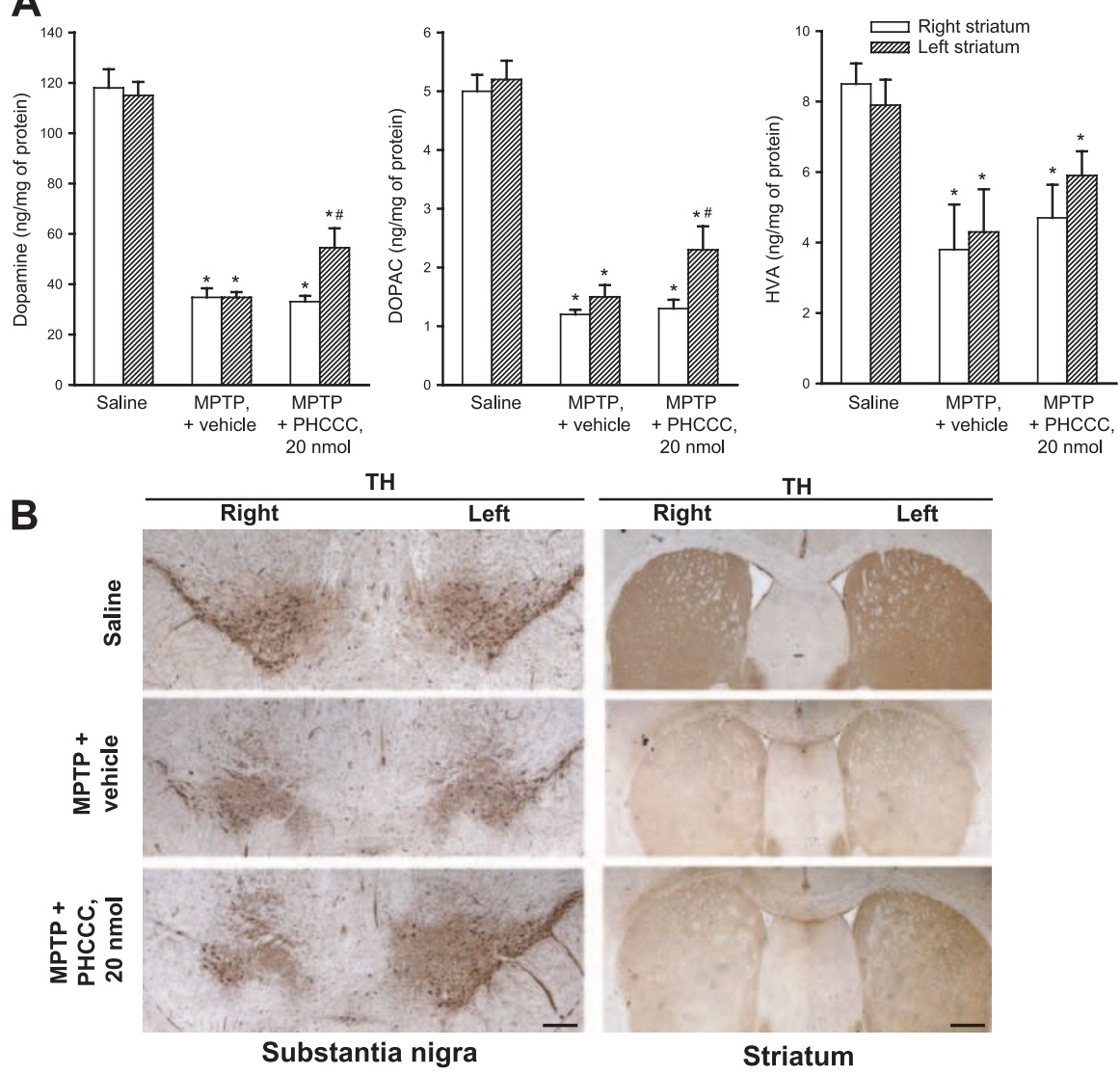

Striatum

C
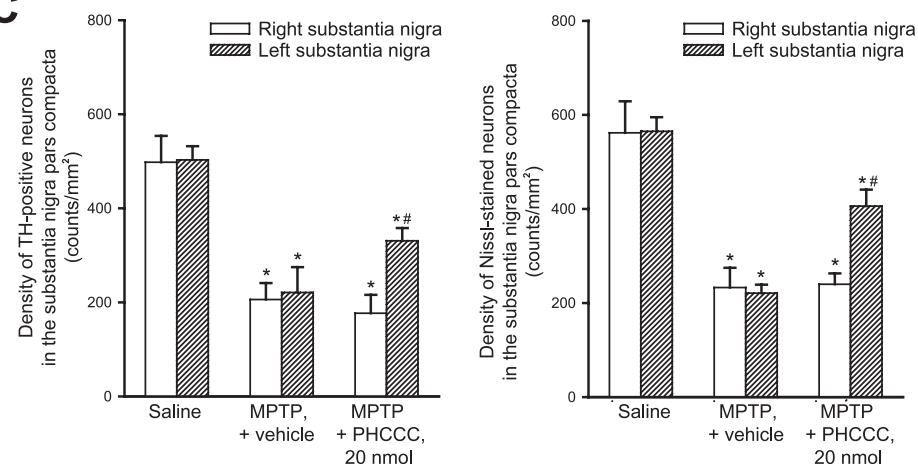

Figure 6. $\boldsymbol{A}$, Striatal dopamine, DOPAC, and HVA levels in C57BL mice injected with MPTP ( $30 \mathrm{mg} / \mathrm{kg}$, i.p., single injection) and unilaterally infused in the left external globus pallidus with vehicle $(0.5 \mathrm{ml}$ of $50 \%$ DMSO in saline) or PHCCC ( $20 \mathrm{nmol} / 0.5 \mathrm{ml}$, dissolved in 50\% DMSO) 30 min before MPTP. Values are mean \pm SEM of $8-10$ determinations; $p<0.05$ (one-way ANOVA and Fisher's PLSD test) versus saline-treated mice $\left(^{*}\right)$ or versus the right uninjected striatum or the left striatum injected with vehicle alone of mice treated with MPTP (\#). B, Immunohistochemical analysis of TH in the corpus striatum and substantia nigra pars compacta of mice treated as above. Scale bars: substantia nigra, $200 \mu \mathrm{m}$; striatum, $400 \mu \mathrm{m}$. C, Quantification of TH-positive neurons and Nissl-stained neurons in the substantia nigra pars compacta calculated as in Figures 2 and 3 . Values are mean \pm SEM of five to six mice. $p<0.05$ (one-way ANOVA and Fisher's PLSD test) versus saline-treated mice $\left({ }^{*}\right)$ or versus the right substantia nigra pars compacta of mice treated with MPTP (\#).

Lewis, 1998). Endogenous activation of excitatory amino acid receptors is permissive to MPTP neurotoxicity, as originally shown by the protective activity of NMDA receptor antagonists in mice infused with $\mathrm{MPP}^{+}$in the pars compacta of the substantia nigra (Turski et al., 1991). Recent evidence suggests that mGlu receptors are involved in mechanisms of neurodegeneration/ neuroprotection in mice challenged with MPTP. Knock-out mice lacking mGlu5 receptors are partially protected against MPTP toxicity, as are mice treated with mGlu1 or mGlu5 receptor antagonists (Aguirre et al., 2001; Battaglia et al., 2004). Pharmaco- logical activation of $m$ Glu $2 / 3$ receptors is also protective, whereas $\mathrm{mGlu} 2 / 3$ receptor blockade amplifies MPTP neurotoxicity (Matarredona et al., 2001; Battaglia et al., 2003). These findings are interesting because mGlu5 receptor antagonists and mGlu2/3 receptor agonists improve motor symptoms in experimental animal models of parkinsonism (Konieczny et al., 1998; Dawson et al., 2000; Kronthaler and Schmidt, 2000; Wolfarth et al., 2000; Lorenc-Koci et al., 2001; Breysse et al., 2002). We decided to examine the role of mGlu4 receptors in MPTP toxicity because these receptors are one the most promising targets for symptomatic drugs in experimental parkinsonism. Activation of mGlu4 receptors suppresses GABA release from the striatopallidal terminals of the indirect pathway, thus relieving motor symptoms of parkinsonism (Marino et al., 2003; Matsui and Kita, 2003; Valenti et al., 2003). mGlu4 receptor agonists/enhancers meet the requirement to be considered as "disease-dependent drugs" because they appear to act specifically on a pathway that is overactive in Parkinson's disease (Marino et al., 2003). Our finding that systemic injection of PHCCC protects nigrostriatal neurons against MPTP toxicity adds additional support to the importance of the mGlu4 receptor as a drug target for the treatment of parkinsonism. PHCCC is a selective positive allosteric modulator of mGlu4 receptors that has already shown neuroprotective activity against NMDA or $\beta$-amyloid toxicity in in vitro models (Maj et al., 2003). Here, we injected PHCCC systemically at doses of 3 or $10 \mathrm{mg} / \mathrm{kg}$. These doses of PHCCC were able to reduce akinesia in mice injected with reserpine $18 \mathrm{~h}$ earlier, suggesting that $\mathrm{PHCCC}$ is centrally active. PHCCC is structurally similar to the mGlu1 receptor antagonist CPCCOEt and antagonizes responses mediated by mGlu1 receptors at relatively high concentrations (>100 mM) (Annoura et al., 1996; Maj et al., 2003). However, CPCCOEt failed to protect against MPTP toxicity (Battaglia et al., 2003), and, more important, PHCCC was inactive in $m G l u 4^{-\prime-}$ mice. Thus, it can be safely concluded that neuroprotection by PHCCC against MPTP toxicity was entirely mediated by mGlu4 receptors. Whether endogenous activation of mGlu4 receptors is protective against MPTP toxicity is unclear. $m G l u 4^{-/-}$mice and Sv129/ CD1 wild-type mice were equally sensitive to nigrostriatal damage induced by $80 \mathrm{mg} / \mathrm{kg}$ MPTP. However, this dose might be too high to unravel a difference between $m \mathrm{Glu}^{-1-}$ and wild-type mice, and an accurate titration of MPTP is needed. In addition, the lack of mGlu4 receptors in knock-out mice might be compensated by adaptive changes involving other group III mGlu receptor subtypes. Interestingly, Valenti et al. (2005) found that 
both mGlu4 and mGlu8 receptors modulate excitatory transmission in mouse substantia nigra pars compacta dopamine neurons and that responses to the mGlu8 receptor agonist (S)-3,4-dicarboxyphenylglycine are amplified in $\mathrm{mGlu}^{-/-}$ mice.

It is remarkable that the extent of neuroprotection seen with systemically injected PHCCC is greater than that found with the mGlu5 receptor antagonist MPEP and with the mGlu2/3 agonist LY379268 ((-)-2-oxa-4-aminocyclo[3.1.0] hexane4,6 -dicarboxylate) in similar studies (Battaglia et al., 2003) (but see Battaglia et al., 2004). Neuroprotection by PHCCC against MPTP toxicity did not result from changes in the kinetics of $\mathrm{MPP}^{+}$formation or in the uptake of $\mathrm{MPP}^{+}$into nerve terminals. It is likely that the drug reduces the excitatory drive to the pars compacta of substantia nigra, thus limiting the excitotoxic component of MPTP toxicity (Turski et al., 1991; Srivastava et al., 1993; Lange and Riederer, 1994; Sonsalla et al., 1998). This may originate from (1) a reduced release of GABA in the external globus pallidus leading to inhibition of subthalamic glutamatergic neurons projecting to the pars compacta of substantia nigra (Marino et al., 2003; Matsui and Kita, 2003; Valenti et al., 2003), or (2) a reduced glutamate release in the pars compacta of substantia nigra mediated by presynaptic mGlu4 receptors (Valenti et al., 2005). Infusion of PHCCC into the external globus pallidus protected the ipsilateral nigrostriatal pathway against MPTP toxicity to an extent similar to that found after systemic injection of the drug. This indicates that the external globus pallidus primarily mediates neuroprotection by systemic PHCCC.

We agree with the belief (Marino et al., 2003) that mGlu4 receptor enhancers are excellent candidates as novel drugs in the treatment of experimental parkinsonism and encourage additional studies in which these drugs are administered alone or in combination with L-DOPA in primate models of parkinsonism.

\section{References}

Aguirre JA, Andbjer B, Gonzalez-Baron S, Hansson A, Stromberg I, Agnati LF, Fuxe K (2001) Group I mGluR antagonist AIDA protects nigral DA cells from MPTP-induced injury. NeuroReport 12:2615-2617.

Annoura H, Fukunaga A, Uesugi M, Tatsuoka T, Horikawa Y (1996) A novel class of antagonists for metabotropic glutamate receptors, 7-(hydroxyimino)cyclopropa[b]chromen1a-carboxylates. Bioorg Med Chem Lett 6:7763-7766.
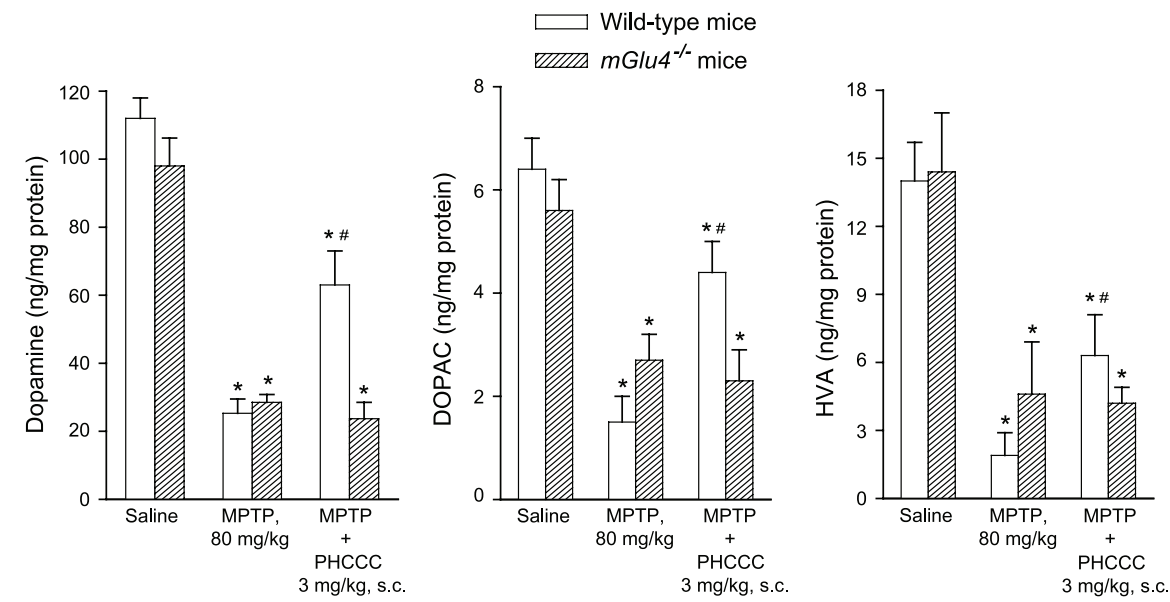

Figure 7. Striatal dopamine, DOPAC, and HVA levels in Sv129/CD1 wild-type and $m G / u 4^{-/-}$mice injected with MPTP (4 intraperitoneal injections of $20 \mathrm{mg} / \mathrm{kg}$ with $2 \mathrm{~h}$ of interval) alone or in combination with PHCCC (3 mg/kg, dissolved in cremophor EL and injected subcutaneously 30 min before each MPTP injection). Values are mean \pm SEM of five to seven determinations; $p<$ 0.05 (one-way ANOVA and Fisher's PLSD test) versus saline-treated mice $\left(^{*}\right)$ or versus mice treated with MPTP alone (\#).

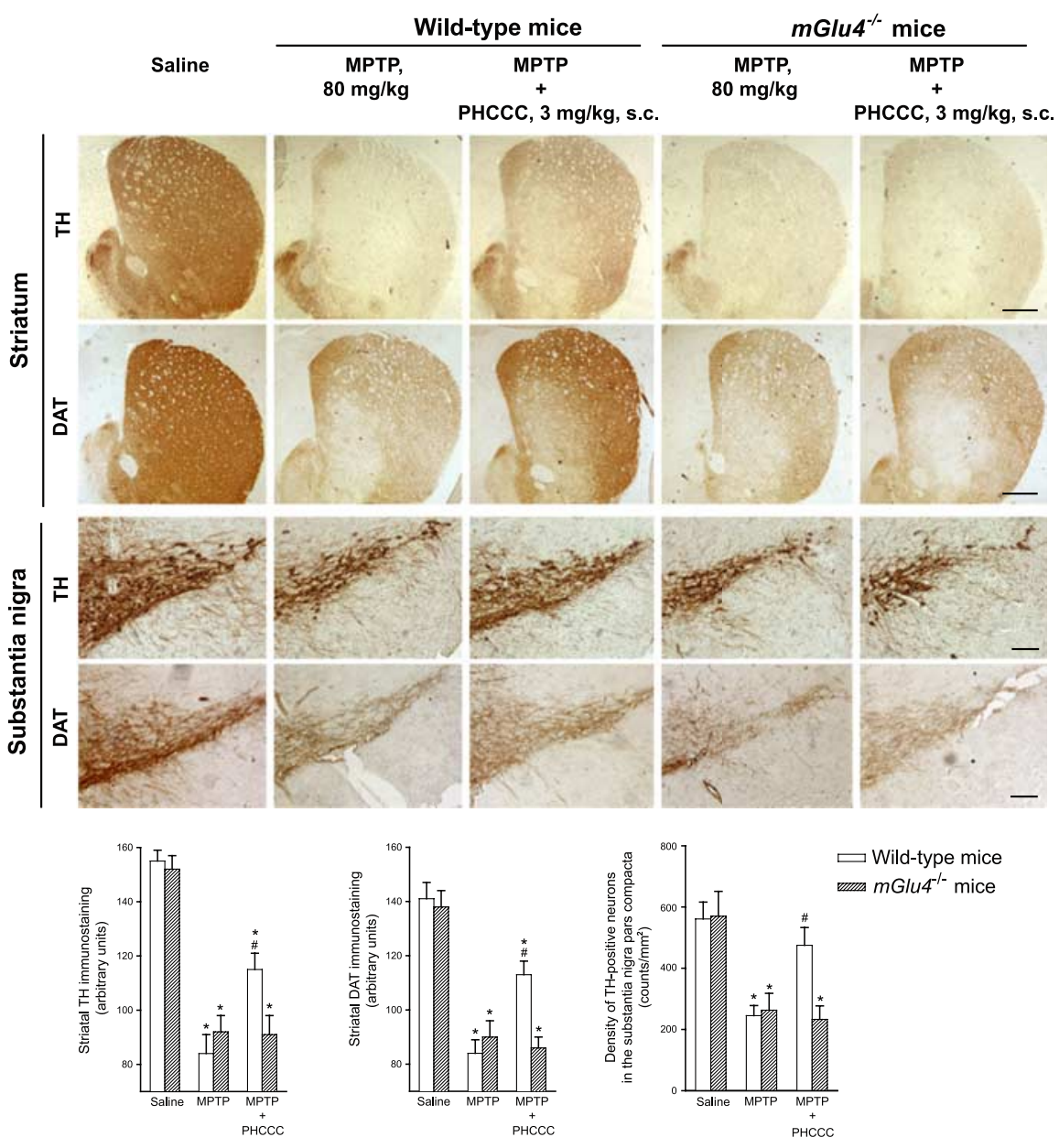

Figure 8. Immunohistochemical analysis of TH and DAT in the corpus striatum and pars compacta of substantia nigra of mice treated with MPTP with or without PHCCC ( $3 \mathrm{mg} / \mathrm{kg}$, dissolved in cremophor EL and injected subcutaneously 30 min before each MPTP injection). Scale bars: TH and DAT in the striatum, $400 \mu \mathrm{m}$; TH and DAT in the substantia nigra, $100 \mu \mathrm{m}$. Densitometric data are shown below. The density of TH-positive neurons in the pars compacta of the substantia nigra was determined as in Figure 2 . Values (means \pm SEM) were calculated from 9-11 mice per group. $p<0.05$ (one-way ANOVA and Fisher's PLSD test) versus control mice $\left(^{*}\right)$ or mice treated with MPTP alone (\#). 
Battaglia G, Busceti LC, Pontarelli F, Fornai F, Paparelli A, Bruno V, Ruggieri S, Nicoletti F (2003) Protective role of group-II metabotropic glutamate receptors against nigro-striatal degeneration induced by 1-methyl-4phenyl-1,2,3,6-tetrahydropyridine in mice. Neuropharmacology 45:155-166.

Battaglia G, Busceti LC, Molinaro G, Biagioni F, Storto M, Fornai F, Nicoletti F, Bruno V (2004) Endogenous activation of mGlu5 metabotropic glutamate receptors contributes to the development of nigro-striatal damage induced by 1-methyl-4-phenyl-1,2,3,6-tetrahydropyridine in mice. J Neurosci 24:828-835.

Bedard PJ, Blanchet PJ, Levesque D, Soghomonian JJ, Grondin R, Morissette M, Goulet M, Calon F, Falardeau P, Gomez-Mancilla B, Doucet JP, Robertson GS, Di Paolo T (1999) Pathophysiology of L-dopa-induced dyskinesias. Mov Dis 14 [Suppl 1]:4-8.

Bonnet JJ, Costentin J (1989) Correlation between $\left[{ }^{3} \mathrm{H}\right]$-dopamine specific uptake and $\left[{ }^{3} \mathrm{H}\right]$-GBR 12783 specific binding during the maturation of rat striatum. Life Sci 44:1759-1765.

Breysse N, Baunez C, Spooren W, Gasparini F, Amalric M (2002) Chronic but not acute treatment with a metabotropic glutamate 5 receptor antagonist reverses the akinetic deficits in a rat model of parkinsonism. J Neurosci 22:5669-5678.

Bruno V, Battaglia G, Copani A, D’Onofrio M, Di Iorio P, De Blasi A, Melchiorri D, Flor JP, Nicoletti F (2001) Metabotropic glutamate receptor subtypes as targets for neuroprotective drugs. J Cereb Blood Flow Metab 21:1013-1033.

Conn PJ, Battaglia G, Marino MJ, Nicoletti F (2005) Metabotropic glutamate receptors in the basal ganglia motor circuit. Nat Rev Neurosci 6:787-798.

Dawson L, Chadha A, Megalou M, Duty S (2000) The group II metabotropic glutamate receptor agonist, DCG-IV, alleviates akinesia following intranigral or intraventricular administration in the reserpine-treated rat. Br J Pharmacol 129:541-546.

De Blasi A, Conn PJ, Pin J, Nicoletti F (2001) Molecular determinants of metabotropic glutamate receptor signaling. Trends Pharmacol Sci 22:114-120.

Fornai F, Alessandri MG, Torracca MT, Bassi L, Corsini GU (1997) Effects of noradrenergic lesions on MPTP/MPP ${ }^{+}$kinetics and MPTP-induced nigrostriatal dopamine disorders. J Pharmacol Exp Ther 283:100-107.

Franklin KBJ, Paxinos G (1997) The mouse brain in stereotaxic coordinates. London: Academic.

Graham DG (1978) Oxydative pathway for catecholamines in the genesis of neuromelanin and cytotoxic quinones. Mol Pharmacol 14:633-643.

Konieczny J, Ossowska K, Wolfarth S, Pilc A (1998) LY354740, a group II metabotropic glutamate receptor agonist with potential antiparkinsonian properties in rats. Naunyn Schmiedebergs Arch Pharmacol 358:500-502.

Kronthaler UO, Schmidt WJ (2000) Activation of striatal group II metabotropic glutamate receptors has a differential effect on dopamine-D1 and -D2 receptor antagonist-induced hypokinesia in the rat. Naunyn Schmiedebergs Arch Pharmacol 361:289-297.

Lange KW, Riederer P (1994) Glutamatergic drugs in Parkinson's disease. Life Sci 55:2067-2075.

Lorenc-Koci E, Wardas J, Wolfarth S, Pilc A (2001) (S)-4C3HPG, a mixed group I mGlu receptor antagonist and a group II agonist, administered intrastriatally, counteracts parkinsonian-like muscle rigidity in rats. Brain Res 903:177-184.
Lowry OH, Rosebrough NY, Farr AL, Randall RY (1951) Protein measurement with Folin phenol reagent. J Biol Chem 193:265-275.

Mac Innes N, Messenger MJ, Duty S (2004) Activation of group III metabotropic glutamate receptors in selected regions of the basal ganglia alleviates akinesia in the reserpine-treated rats. Br J Pharmacol 141:15-22.

Maj M, Bruno V, Dragic Z, Battaglia G, Inderbitzin W, Stein T, Gasparini F, Kuhn R, van der Putten H, Nicoletti F, Flor JP (2003) (-)-PHCCC, a positive allosteric modulator selective for metabotropic glutamate receptor subtype 4: pharmacological and molecular characterization. Neuropharmacology 45:895-906.

Marino MJ, Williams Jr DL, O’Brien JA, Valenti O, Mc Donald TP, Clements MK, Wang R, Di Lella AG, Hess JF, Kinney GG, Conn PJ (2003) Allosteric modulation of group III metabotropic glutamate receptor 4: a potential approach to Parkinson's disease treatment. Proc Natl Acad Sci USA 100:13668-13673.

Matarredona ER, Santiago M, Venero JL, Cano J, Machado A (2001) Group II metabotropic glutamate receptor activation protects striatal dopaminergic nerve terminals against $\mathrm{MPP}^{+}$-induced neurotoxicity along with brain-derived neurotrophic factor induction. J Neurochem 76:351-360.

Matsui T, Kita H (2003) Activation of group III metabotropic glutamate receptors presynaptically reduces both GABAergic and glutamatergic transmission in the rat globus pallidus. Neuroscience 122:727-737.

Pin JP, Duvoisin R (1995) The metabotropic glutamate receptors: structure and functions. Neuropharmacology 34:1-26.

Przedporski S, Jackson-Lewis V (1998) Mechanisms of MPTP toxicity. Mov Dis 13 [Suppl 1]:35-38.

Rascol O (2000) The pharmacological therapeutic management of levodopa-induced dyskinesias in patients with Parkinson's disease. J Neurol 247 [Suppl 2]:II51-II57.

Rivas E, de Ceballos ML, Nieto O, Fontenla JA (1999) In vivo effects of new inhibitors of catechol-O-methyl transferase. $\mathrm{Br} \mathrm{J}$ Pharmacol 126:1667-1673.

Sonsalla PK, Alberts DS, Zeevalk GD (1998) Role of glutamate in neurodegeneration of dopamine neurons in several animal models of parkinsonism. Amino Acids 14:69-74.

Srivastava R, Brouillet E, Beal MF, Storey E, Hyman BT (1993) Blockade of 1-methyl-4-phenylpyridinium ion $\left(\mathrm{MPP}^{+}\right)$nigral toxicity in the rat by prior decortication or MK-801 treatment: a stereological estimate of neuronal loss. Neurobiol Aging 14:295-301.

Thiruchelvam MJ, Powers JM, Cory-Slechta DA, Richfield EK (2004) Risk factors for dopaminergic neuron loss in human $\alpha$-synuclein transgenic mice. Eur J Neurosci 19:845-854.

Turski L, Bressler K, Rettig KJ, Loschmann PA, Wachtel H (1991) Protection of substantia nigra from $\mathrm{MPP}^{+}$neurotoxicity by $N$-methyl-Daspartate antagonists. Nature 349:414-418.

Valenti O, Marino MJ, Wittmann M, Lis E, Di Lella AG, Kinney GG, Conn PJ (2003) Group III metabotropic glutamate receptor-mediated modulation of the striatopallidal synapse. J Neurosci 23:7218-7226.

Valenti O, Mannaioni G, Seabrook GR, Conn PJ, Marino MJ (2005) Group III metabotropic glutamate receptor-mediated modulation of excitatory transmission in rodent substantia nigra pars compacta dopamine neurons. J Pharmacol Exp Ther 313:1296-1304.

Wolfarth S, Konieczny J, Lorenc-Koci E, Ossowska K, Pilc A (2000) The role of metabotropic glutamate receptor (mGluR) ligands in parkinsonian muscle rigidity. Amino Acids 19:95-101. 